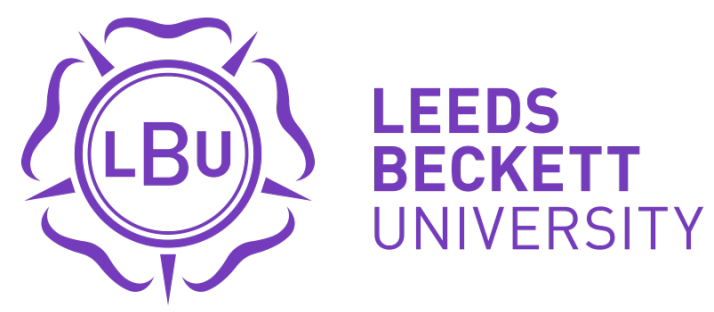

Citation:

Manley, AJ and Lavender, T and Smith, DM (2015) Processing fluency effects: can the content and presentation of participant information sheets influence recruitment and participation for an antenatal intervention? Patient education and counseling, 98 (3). 391 - 394. ISSN 0738-3991 DOI: https://doi.org/10.1016/j.pec.2014.11.005

Link to Leeds Beckett Repository record:

https://eprints.leedsbeckett.ac.uk/id/eprint/183/

Document Version:

Article (Updated Version)

The aim of the Leeds Beckett Repository is to provide open access to our research, as required by funder policies and permitted by publishers and copyright law.

The Leeds Beckett repository holds a wide range of publications, each of which has been checked for copyright and the relevant embargo period has been applied by the Research Services team.

We operate on a standard take-down policy. If you are the author or publisher of an output and you would like it removed from the repository, please contact us and we will investigate on a case-by-case basis.

Each thesis in the repository has been cleared where necessary by the author for third party copyright. If you would like a thesis to be removed from the repository or believe there is an issue with copyright, please contact us on openaccess@leedsbeckett.ac.uk and we will investigate on a case-by-case basis. 
Running Head: Processing Fluency Effects in Participant and Patient Recruitment

\title{
Processing fluency effects: can the content and presentation of participant information sheets influence recruitment and participation for an antenatal intervention?
}

\author{
Andrew J. Manley ${ }^{\mathrm{a}}$, Tina Lavender ${ }^{\mathrm{b}}$ and Debbie M. Smith ${ }^{\mathrm{c}}$
}

\author{
${ }^{a}$ Research Institute for Sport, Physical Activity \& Leisure, Leeds Beckett University, Leeds, \\ UK. \\ ${ }^{\mathrm{b}}$ The School of Nursing, Midwifery and Social Work, The University of Manchester, \\ Manchester, UK. \\ ${ }^{\mathrm{c}}$ The School of Psychological Sciences, The University of Manchester, Manchester, UK.
}

*Please address correspondence to: Andrew J. Manley, Research Institute for Sport, Physical Activity \& Leisure, Leeds Beckett University, Fairfax Hall, Headingley Campus, Leeds, West Yorkshire, LS6 3QS, UK.

Tel: +44 113812 4717; Fax: +44 113283 7575; E-mail: A.J.Manley@leedsbeckett.ac.uk 


\begin{abstract}
Objective: To assess the extent to which the title and font of participant information sheets (PISs) can influence pregnant women's and trainee midwives' perceptions of an antenatal intervention.
\end{abstract}

Methods: Pregnant women $(n=35)$ and trainee midwives $(n=36)$ were randomly presented with one of four PISs where the title and font of the PIS had been manipulated to create four experimental conditions (i.e., Double-Fluent; Double-Awkward; Fluent Title-Awkward Font; Awkward Title-Fluent Font). After reading the PIS, participants rated their perceptions of the intervention (i.e., attractiveness, complexity, expected risk, required effort) using five-point Likert scales.

Results: A 4x2 factorial multivariate analysis of variance revealed that pregnant women rated the Double-Awkward condition as significantly more complex than the Double-Fluent ( $p=$ $.024)$ and Awkward Title-Fluent Font $(p=.021)$ conditions.

Conclusion: Font influenced pregnant women's ratings of intervention complexity.

Practice Implications: Results have implications for ethical recruitment, and in turn, the optimisation of corresponding interventions.

Keywords: cognitive processes; intervention studies; judgment; participant recruitment; professional standards; research ethics. 


\section{Introduction}

When we are able to process written information with ease, we assume the information will be easy to implement. For example, when exercise instructions are easy to read (e.g., font such as Arial), people are more willing to incorporate the exercises within their daily routine than when the same instructions are presented in a font that is more difficult to read (e.g., Brush Script MT [1]). Furthermore, labels or acronyms which are easy to read/pronounce (e.g., Chunta) elicit greater perceptions of familiarity and lower perceived risk than those which are difficult to read/pronounce (e.g., Tsiischili [2,3]). The occurrence of these processing fluency effects may be due to our reliance on familiarity-based heuristics (i.e., a naïve mechanism by which fluently-processed material is interpreted to be more familiar) during cognitive operations [4]. If fluently processed material is judged as familiar, it is more likely to be accepted [5] and less likely to be scrutinised [6]. The present study will explore the implications of processing fluency effects in relation to something that is ubiquitous within efforts to advance and improve patient education and care: participant recruitment to intervention studies.

Participant information sheets (PISs) inform prospective participants about the nature of an intervention, ensuring methodological rigour and ethical requirements (i.e., informed consent) are upheld. Professional bodies in the UK $[7,8]$ have produced guidelines for the development of appropriate PISs and consent forms. However, recommended strategies included within these and other evidence-based guidelines for the clear communication of participation risks and benefits $[9,10]$ do not explicitly consider the potential impact of processing fluency effects.

Song and Schwarz $[2,11]$ suggested that professionals including policy makers and product manufacturers may want to harness fluency effects to not only emphasise specific 
advantages of purchasing certain products, but also warn consumers of potential hazards that might otherwise appear innocuous. Similarly, researchers and health professionals may find that fluency effects represent an effective and ethical means of presenting important intervention information to participants.

The study will explore if PIS title and font influences trainee midwives' and pregnant women's initial perceptions (e.g., attractiveness, complexity, required effort, level of risk) of an antenatal intervention designed for pregnant women with a BMI $\geq 30 \mathrm{~kg} / \mathrm{m}^{2}$. It was hypothesised that PISs presented using "fluent" (i.e., easy-to-process) written information would be perceived by participants as more attractive, less complex, less risky, and less effortful to implement compared with PISs presented using "awkward" (i.e., difficult-toprocess) written information.

\section{Methodology}

\subsection{Design}

This cross-sectional between-groups study involved randomisation at the level of the participant to one of four experimental conditions.

\subsection{Sample}

Pre-study and post-hoc power calculations [12] indicated a total sample size of 32 (i.e., 16 participants per sub-sample) was sufficient. Participants (recruited over two weeks) were:

a) Pregnant women with an antenatal booking $\mathrm{BMI} \geq 30 \mathrm{~kg} / \mathrm{m}^{2}$ receiving antenatal care in Greater Manchester, UK $(n=35)$;

b) Trainee midwives (i.e., future gatekeepers to interventions for the target group) in the final year of study at a UK University $(n=36)$.

The following exclusion criteria were applied to the sample: under the age of 18; not fluent in reading written English; blind or partially sighted. 


\subsection{Procedure and materials}

A multi-disciplinary team designed and conducted this study. Ethical approval was obtained from the NHS (11/H1016/4), the local NHS Trust Research and Development department (11OBS01), and The University of Manchester Research Ethics Committee. All participants were recruited by the same research midwife.

Following informed consent, participants were randomly assigned to one of four experimental conditions and presented with a sealed envelope (ensuring the study was double-blind) containing the experimental stimuli (i.e., PIS outlining details of an antenatal intervention for pregnant women with a $\mathrm{BMI} \geq 30 \mathrm{~kg} / \mathrm{m}^{2}$ ) and a corresponding rating sheet. The four experimental conditions (as depicted in Figure 1) were as follows:

Double fluent condition: Title of programme easy to pronounce and information sheet presented in easy-to-read font (i.e., 12 point Arial);

Double awkward condition: Title of programme difficult to pronounce and information sheet presented in difficult-to-read font (i.e., 12 point Mistral);

Fluent title-awkward font condition: Title of programme easy to pronounce and information sheet presented in difficult-to-read font (i.e., 12 point Mistral); Awkward title-fluent font condition: Title of programme difficult to pronounce and information sheet presented in easy-to-read font (i.e., 12 point Arial). 
(a) The Lifestyle Course (TLC): An antenatal programme for women with a Body Mass Index (BMI) of 30 or more.

(b) An explanatory sandanised control trial to evaluate the impact of attending The lifestyle Cousse (TLC) on the heabth of pregnant wamen with a Body Mass Index (BMI) $\geq 30 \mathrm{~kg} / \mathrm{m}^{2}$ and their balies.

(c) The lifestyle Cousse (TLC): An antenatal programme for wamen with a Body Mass Index (BMI) of 30 ar mase.

(d) An explanatory randomised control trial to evaluate the impact of attending The Lifestyle Course (TLC) on the health of pregnant women with a Body Mass Index $(\mathrm{BMI}) \geq 30 \mathrm{~kg} / \mathrm{m}^{2}$ and their babies.

FIGURE 1. Examples of how written information was presented in all four experimental conditions: $(a)=$ Double fluent, $(b)=$ Double awkward, $(c)=$ Fluent title-awkward font, $(d)=$ Awkward title-fluent font.

After reading the PIS, participants were asked to rate their perceptions of the intervention on a five-point Likert scale ( $1=$ low; $5=$ high), in terms of Attractiveness (i.e., intention to participate/refer), Complexity (i.e., ease/difficulty to understand details of the intervention), Expected Risk (i.e., level of perceived risk associated with participation), and Required Effort (i.e., level of effort required to fulfil participation requirements). The questionnaire was developed based on those used in previous investigations of processing fluency effects $[1,2,6]$. 


\section{Results}

A 4 (processing fluency condition) x 2 (population sub-sample) factorial multivariate analysis of variance (MANOVA) was conducted (means and standard deviations are presented in Table 1). The results indicated a significant effect for population sub-sample, Pillai's trace $=.234, F_{5,58}=3.55, p=.007$, partial $\eta^{2}=.23$; a non-significant effect for fluency condition, Pillai's trace $=.315, F_{15,180}=1.41, p=.147$, partial $\eta^{2}=.11$; and a significant interaction between population sub-sample and fluency condition, Pillai's trace $=.400, F_{15,180}$ $=1.84, p=.032$, partial $\eta^{2}=.13$. 
TABLE 1. Mean perceptions of attractiveness, complexity, expected risk and required effort associated with an antenatal intervention, as reported by pregnant women and trainee midwives across four conditions of processing fluency.

\begin{tabular}{|c|c|c|c|c|c|c|c|c|}
\hline \multirow[b]{2}{*}{ Dependent Variable } & \multicolumn{8}{|c|}{ Population Sub-sample $x$ Processing Fluency Condition } \\
\hline & $\begin{array}{c}\text { Pregnant } \\
\text { Women- } \\
\text { DF } \\
(n=9)\end{array}$ & $\begin{array}{c}\text { Pregnant } \\
\text { Women- } \\
\text { DA } \\
(n=9)\end{array}$ & $\begin{array}{c}\text { Pregnant } \\
\text { Women- } \\
\text { FTAF } \\
(n=8)\end{array}$ & $\begin{array}{c}\text { Pregnant } \\
\text { Women- } \\
\text { ATFF } \\
(n=8)\end{array}$ & $\begin{array}{c}\text { Trainee } \\
\text { Midwives- } \\
\text { DF } \\
(n=9)\end{array}$ & $\begin{array}{c}\text { Trainee } \\
\text { Midwives- } \\
\text { DA } \\
(n=10)\end{array}$ & $\begin{array}{c}\text { Trainee } \\
\text { Midwives- } \\
\text { FTAF } \\
(n=9)\end{array}$ & $\begin{array}{c}\text { Trainee } \\
\text { Midwives- } \\
\text { ATFF } \\
(n=8)\end{array}$ \\
\hline Attractiveness & $\begin{array}{c}4.22 \\
(0.66)\end{array}$ & $\begin{array}{c}4.00 \\
(0.87)\end{array}$ & $\begin{array}{c}3.75 \\
(0.85)\end{array}$ & $\begin{array}{c}3.94 \\
(0.68)\end{array}$ & $\begin{array}{c}3.95 \\
(0.46)\end{array}$ & $\begin{array}{c}4.00 \\
(0.62)\end{array}$ & $\begin{array}{c}4.11 \\
(0.65)\end{array}$ & $\begin{array}{c}4.13 \\
(0.82)\end{array}$ \\
\hline Complexity & $\begin{array}{c}0.56 \\
(0.58)\end{array}$ & $\begin{array}{c}1.72 * \\
(1.03)\end{array}$ & $\begin{array}{c}0.94 \\
(0.94)\end{array}$ & $\begin{array}{c}0.50 \\
(0.46)\end{array}$ & $\begin{array}{c}0.94 \\
(0.58)\end{array}$ & $\begin{array}{c}1.40 \\
(0.88)\end{array}$ & $\begin{array}{c}1.94 \\
(1.26)\end{array}$ & $\begin{array}{c}0.94 \\
(0.42)\end{array}$ \\
\hline Expected Risk & $\begin{array}{c}0.83 \\
(0.61)\end{array}$ & $\begin{array}{c}0.78 \\
(0.83)\end{array}$ & $\begin{array}{c}0.63 \\
(0.58)\end{array}$ & $\begin{array}{c}0.63 \\
(0.44)\end{array}$ & $\begin{array}{c}0.89 \\
(0.65)\end{array}$ & $\begin{array}{c}0.70 \\
(0.48)\end{array}$ & $\begin{array}{c}1.06 \\
(0.77)\end{array}$ & $\begin{array}{c}1.56 \\
(0.98)\end{array}$ \\
\hline Required Effort & $\begin{array}{c}3.17 \\
(0.97)\end{array}$ & $\begin{array}{c}3.33 \\
(0.94)\end{array}$ & $\begin{array}{c}3.19 \\
(0.80)\end{array}$ & $\begin{array}{c}3.00 \\
(0.89)\end{array}$ & $\begin{array}{c}3.22 \\
(0.87)\end{array}$ & $\begin{array}{c}2.60 \\
(0.46)\end{array}$ & $\begin{array}{c}3.17 \\
(0.75)\end{array}$ & $\begin{array}{c}3.19 \\
(1.07)\end{array}$ \\
\hline
\end{tabular}

Note. Standard deviations are in parentheses. $* p<.05$.

$\mathrm{DF}=$ Double Fluent condition; DA = Double Awkward condition; FTAF $=$ Fluent Title-Awkward Font condition; ATFF $=$ Awkward Title-Fluent Font condition. 
There were no significant differences between fluency conditions for trainee midwives' ratings: Attractiveness, $F_{3,32}=0.20, p=.899$, partial $\eta^{2}=.02$; Complexity, $F_{3,32}=2.72, p=$ .061 , partial $\eta^{2}=.20 ;$ Expected Risk, $F_{3,32}=2.23, p=.104$, partial $\eta^{2}=.17$; Required Effort, $F_{3,32}=1.33, p=.282$, partial $\eta^{2}=.11$. However, results for pregnant women's ratings revealed a significant difference for Complexity, $F_{3,30}=4.41, p=.011$, partial $\eta^{2}=.31$. Follow-up post-hoc tests with a Bonferroni adjustment showed that the Double Awkward condition was rated as significantly more complex than both the Double Fluent $(p=.024)$ and Awkward Title-Fluent Font $(p=.021)$ conditions. No other significant differences were found for pregnant women's ratings between conditions: Attractiveness, $F_{3,30}=.55, p=.655$, partial $\eta^{2}=.05$; Expected Risk, $F_{3,30}=.24, p=.871$, partial $\eta^{2}=.02$; Required Effort, $F_{3,30}=$ $.19, p=.900$, partial $\eta^{2}=.02$.

\section{Discussion and Conclusion}

\subsection{Discussion}

The findings did not support the majority of the hypotheses. However, a significant difference was demonstrated for pregnant women in relation to perceptions of complexity. Specifically, if PISs were presented in a "fluent" font, pregnant women perceived the 
intervention to be less complex compared to when PISs included a title and font that were "awkward". This supports previous reports of an inverse relationship between the fluency of written instructions and the perceived complexity of implementing those instructions [1].

Considering the differences in perceived complexity between population sub-groups, a tentative explanation is that trainee midwives' broader knowledge base of specific issues (e.g., importance of ethical conduct) may have made them less reliant on familiarity-based heuristics when reading PISs. This aligns with contentions from expectancy and social cognitive theorists $[13,14,15]$ that expectancies of events and associated outcomes are determined by a person's previous direct experience, declarative knowledge (i.e., knowledge derived from factual information and/or existing beliefs), and procedural knowledge (i.e., awareness of context-specific rules and strategies). Further research is required to verify the above interpretation.

One recommendation for future research is to collect qualitative data to facilitate a deeper understanding of participants' PIS-elicited perceptions of interventions. Another promising avenue is to consider the interaction between the processing fluency of written and verbal information, thus enhancing the authenticity of the participant recruitment process [8] within the confines of experimental enquiry. Finally, future studies should account for participant demographics (e.g., reading ability) as potential mediators of fluency effects.

\subsection{Conclusion}

PISs presented in a fluent font led pregnant women to perceive the intervention as less complex/easier to understand. However, this effect was not observed for gatekeepers, suggesting that prior contextual experience/knowledge may off-set reliance on familiaritybased heuristics.

\subsection{Practice Implications}


In line with suggestions that perceived complexity can influence injured athletes' adherence to rehabilitation programmes [16,17], similar perceptions may guide pregnant women's decisions in relation to potentially beneficial interventions. Moreover, the effective and ethical recruitment of participants to interventions is an essential part of the evidence bases which underpin the practice of health professionals. In light of these findings, practitioners should present PISs in a fluent manner (i.e., easy-to-read font/title), thus optimising participant recruitment.

\section{Acknowledgments}

The authors' would like to thank Wendy Taylor for her assistance in recruiting participants and collecting data. We are also very grateful to the participants, the maternity unit, and our respective Universities for supporting this particular research study. 


\section{References}

[1] H. Song, N. Schwarz, If it's hard to read, it's hard to do; processing fluency affects effort prediction and motivation, Psychol. Sci. 19 (2008) 986-8.

[2] H. Song, N. Schwarz, If it's difficult to pronounce, it must be risky; fluency, familiarity and risk perception, Psychol. Sci. 20 (2009) 135-8.

[3] A.L. Alter, D.M. Oppenheimer, Predicting short-term stock fluctuations by using processing fluency, P. Natl. Acad. Sci. 103 (2006) 9369-72.

[4] H. Park, L.M. Reder, Moses illusion, in: R.F. Pohl (Ed.), Cognitive Illusions, Psychology Press, New York, 2003, pp. 275-92.

[5] N. Schwarz, L. Sanna, I. Skurnik, C. Yoon, Metacognitive experiences and the intricacies of setting people straight: Implications for debiasing and public information campaigns, Adv. Exp. Soc. Psychol. 39 (2007) 127-61.

[6] H. Song, N. Schwarz, Fluency and the detection of misleading questions: Low processing fluency attenuates the Moses illusion, Soc. Cognition. 26 (2008) 791-9.

[7] National Research Ethics Service, Guidance on the Design of Participant Information Sheets and Consent Forms, 2011, URL:http://www.nres.nhs.uk/applications/guidance/consent-guidance-andforms/?1311929 entryid62=67013 (Accessed 19th July 2012).

[8] Royal College of Nursing, Informed Consent in Health and Social Care Research, 2011, URL:http://www.rcn.org.uk/ data/assets/pdf file/0010/78607/002267.pdf (Accessed 19th July 2012).

[9] J. Paling, Strategies to help patients understand risk, Brit. Med. J. 327 (2003) 745-8.

[10] R. Thomson, A. Edwards, J. Grey, Risk communication in the clinical consultation, Clin. Med. 5 (2005) 465-9. 
[11] H. Song, N. Schwarz, If it's easy to read, it's easy to do, pretty, good, and true, Psychologist. 23 (2010) 108-11.

[12] F. Faul, E. Erdfelder, A. Buchner, A.-G. Lang, Statistical power analyses using G*Power 3.1: Tests for correlation and regression analyses, Behav. Res. Meth. 41 (2009) 1149-60.

[13] J.R. Anderson, The Architecture of Cognition, Harvard University Press, Cambridge, MA, 1983.

[14] A. Bandura, Social Foundations of Thought and Action: A Social Cognitive Theory, Prentice-Hall, Englewood Cliffs, NJ, 1986.

[15] J.M. Olson, N.J. Roese, M.P. Zanna, Expectancies, in: E.T. Higgins, A.W. Kruglanski (Eds.), Social Psychology: Handbook of Basic Principles, The Guildford Press, New York, 1996, pp. 211-38.

[16] A. Niven, Rehabilitation adherence in sport injury: Sport physiotherapists' perceptions, J. Sport Rehabil. 16 (2007) $93-110$.

[17] E. Udry, M.B. Andersen, Athletic injury and sport behaviour, in: T.S. Horn (Ed.), Advances in Sport Psychology, third ed., Human Kinetics, Champaign, IL, 2008, pp. 401-22. 